\title{
Tracking patient journeys to enhance service development and resource allocation Joe Scuteri* and Lisa Fodero
}

\author{
Address: 4409/93 Liverpool Street, Sydney, NSW, 2000, Australia \\ Email: Joe Scuteri* - joe.scuteri@healthconsult.com.au \\ * Corresponding author
}

from 24th Patient Classification Systems International (PCSI) Working Conference Lisbon, Portugal. 8-II October 2008

Published: 27 November 2008

BMC Health Services Research 2008, 8(Suppl I):A9 doi:I0.I 186/1472-6963-8-SI-A9

This abstract is available from: http://www.biomedcentral.com/I472-6963/8/SI/A9

(c) 2008 Scuteri and Fodero; licensee BioMed Central Ltd.

\section{Introduction}

NSW Health is undertaking the community health and outpatient care information project (CHOCIP), which will develop a patient-level data collection across selected services in NSW. It is the largest project of its type attempted in Australia and will result in the collection of 25 million unit records describing services provided in community health and outpatient care. The business rules of the sub-project are aimed at developing a structure for collecting data on the interactions that a patient has with the public health system in respect of a set of related problems or issues. The rules will allow the resultant patientlevel data to be used to analyse patient journeys through the health services system in support of planning, service development and resource allocation processes.

\section{Methods}

The methodology consisted of five stages. First, existing business rules were reviewed for relevant data collections including the NSW Health aggregate data collection system, which counts Non-Admitted Patient Occasions of Service (NAPOOS), and systems that capture patient-level data for specific community health services, to determine their suitability for use in the CHOCIP data collection. Second, data collection processes were analysed to identify issues with existing business rules, including problems relating to their consistent application. Third, business rules were drafted that allow tracking of patient journeys to support data collection and reporting for the CHOCIP data collection. Fourth, the draft business rules were tested and refined using stakeholder workshops. Fifth, documentation was prepared on the business rules for use in developing Policy Directives and Data Collection Guidelines to support the implementation of the CHOCIP data collection.

\section{Results}

By reviewing existing business rules, a variety of approaches were found to define the data collected to describe the workload of community health and outpatient care services. The analysis of data collection processes revealed inconsistent counting practices resulting in the standard unit for workload measurement, the NAPOOS, being largely meaningless and not used for planning or resource allocation purposes. It was also found that the rules developed to make the NAPOOS more comparable across services were not suitable for a patient-level data collection.

Thus, the NAPOOS concept was abandoned and a new concept called a service event, subdivided into individual and group service events, was defined. The service event is the base unit of measure for the data collection, and the unit record data will be collected for each service event. An individual client service event is defined as an instance of service provision by one or more individual health service providers that is targeted to a specific set of problems or issues presented by an individual registered client, and that warrants an entry in that registered client's case notes. A group service event is defined as an instance of service 
provision by one or more individual service providers that is targeted to a specific set of problems or issues shared by two or more registered clients at the group session, and that warrants an entry in each registered client's case notes.

Chapters of services are then defined as a set of one or more service events provided by the same registered health service provider organisation that address the same related set of problems or issues for the same registered client/patient. Chapters of service describe the interactions between a patient and a single service provider unit for the same problem or issue. The interactions between a patient and a number of service provider units are termed a journey, defined as a set of chapters that address the same set of related problems or issues for the same registered patient.

The value of the data collection for service development and resource allocation purposes is enhanced by defining business rules that allow the collection of data for client present and client not-present service events. Typical client not-present service events include case conferences, case management, consultation liaison services, advocacy services, and familial/carer support services. Collection of data on these activities allows a full understanding of the resources applied to the care of patients for a set of related problems or issues.

\section{Conclusion}

Defining business rules for a patient-level data collection is different from defining business rules for aggregate data collection. By defining the hierarchy of concepts as service events, chapters and journeys, the interactions of patients with the health system for the same problem or issue can be analysed. The resultant CHOCIP data will be a rich information source that can be applied to the development or refinement of patient classification systems and associated resource allocation models for community health and outpatient care services.

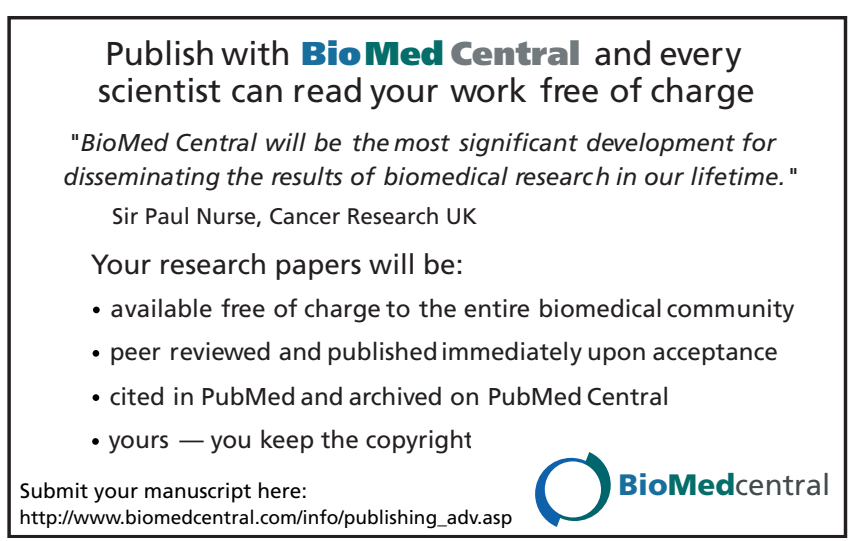

Page 2 of 2

(page number not for citation purposes) 